\title{
Hypersexuality after Modafinil Treatment: A Case Report
}

\author{
Süheyla Doğan Bulut, Rıza Gökçer Tulacı, Semanur Türkoğlu, Serdar Bulut and Sibel Örsel \\ Department of Psychiatry, Ankara Dıskapı Yıldırım Beyazıt Teaching and Research Hospital, Ankara 0600, Turkey
}

\begin{abstract}
Modafinil is employed for the treatment of narcolepsy and other sleep disorders like idiopathic hypersomnia. Modafinil is involved in the modulation of orexin, a hypothalamic neuropeptide that regulates wakefulness. It also indicated that the drug interferes with the activity of additional neurotransmitters like hypocretin, histamine, gamma-aminobutyricacid, glutamate and norepinephrine. Modafinil can also block the dopamine transporter by increasing brain dopamine levels. Common side effects of modafinil include headache, nausea, nervousness, anxiety and trouble sleeping. Other side effects are affective lability, hyposexuality, personality change, aggression, abnormal dreams, irritability, suicidal ideas, mania, hypomania and psychotic exacerbation. In this case report, we present a 45 year old woman with idiopathic hypersomnia which is characterized primarily excessive day time sleepiness. Before modafinil treatment ESS (Epworth Sleepiness Scale) score of patient was 13. Treatment with Modafinil 200 mg daily within two weeks produced a subjective improvement in her daytime sleepiness (ESS score after treatment is 4). But one week after the start of modafinil treatment, her sexual desire increased. Before this treatment, her sexual intercourse frequency was 1-2 times per week and after this treatment she wanted coitus every day. She has continual thoughts about sexuality. She didn't have any additional medication use or medical condition that increase sexual desire. Modafinil dose was decreased $100 \mathrm{mg} / \mathrm{daythen}$ to 50 $\mathrm{mg} /$ day. Her ESS score was 7 and daytime sleepiness had no effect on her life. After decreasing modafinil treatment her sexual desire returned to normal. Hypersexuality has not been reported as a side effect of modafinil yet. The pathophysiological mechanism of modafinil induced hypersexuality is not clear. In conclusion, clinicians should be aware of this rare significant side effect of modafinil and should maintain treatment with the lowest possible dose.
\end{abstract}

Key words: Modafinil, hypersexuality, idiopathic hypersomnia.

\section{Introduction}

Idiopathic hypersomnia is a primary sleep disorder whose cause can not be explained medically and which causes excessive sleepiness at day time although the duration of sleep at night is normal or long. It is thought to be of CNS origin [1]. Modafinil is employed for the treatment of narcolepsy and other sleep disorders such as idiopathic hypersomnia [2].

Modafinil is involved in the modulation of orexin, a hypothalamic neuropeptide that regulates wakefulness [3]. It is also reported that the drug interferes with the activity of additional neurotransmitters such as hypocretin, histamine, gamma-aminobutyricacid, glutamate and norepinephrine. Modafinil can also block the dopamine transporter by increasing brain dopamine levels [4-7]. Common side effects of modafinil include headache, nausea, nervousness,

Corresponding author: Süheyla Doğan Bulut, M.D., research field: psychiatry. E-mail: dr_sdbulut@yahoo.com. anxiety and trouble sleeping. Other side effects are affective lability, hyposexuality, personality change, aggression, abnormal dreams,irritability, suicidal ideas, mania, hypomania and psychotic exacerbation [8].

In this report, a case starting modafinil treatment with the diagnosis of idiopathic hypersomnia and who developed hypersexuality during treatment will be presented and discussed.

\section{Case}

A 45 year old female patient, who is married with two children and is a house wife referred to our outpatient clinic with complaints of excessive sleepness during day time and taking frequent naps continuing for the last year.

In history, it was learned that she slept and woke up at usual times although sleeping at day time as well. During daytime she felt sleepy and needed sleep for additional one-two hours. In history, there was no 
drug use for other diseases, head taruma, neorological disorder or pyschological disorder.

In psychological evaluation, she looked her age. The way of dressing was consistent with hers sociocultural characteristics. Her consciousness was open, cooperative and oriented. Her attention-concentration was complete. She did not describe any perceptual problems. Patient's mood was euthymic. Psyhomotor movements were normal. Her appetite was normal and there were no vegetative symptoms other than daytime sleepiness.

In order to rule out organic conditions such as obstructive apnea syndrome, ENT and respiratory diseases clinics were consulted. In 24-hour continuous polysomnography investigation, latency to REM sleep and percentages of light sleep and REM sleep were normal. Biochemical parameters that can lead to sleep and fatique, TFT and hemogram results were within normal ranges. Neurological examination was normal.

In view of history and psychiatric examination, modafinil $200 \mathrm{mg} /$ day treatment was commenced with the diagnosis of idiopathic insomnia. Her ESS score was 13 before the administering of modafinil was 13 . At the control visit 14 days later, it was learned that day time sleepiness and the frequency of short naps during the day decreased. ESS score decreased to 4. She stated that about one week after initiating drug use her sexual desire increased. Before this treatment her sexual intercourse frequency was 2-3 times per week and after this treatment she wants coitus every day. She had continual thoughts about sexuality. She complained of this condition and stated that it was also a problem for her husband who is 75 years old.

There was no history of additional drug or substance use which can cause the development of hypersexuality. Neurological examination and brain imaging were evaluated as normal.

Thinking that hypersexuality may be associated with modafinil use, dose was first reduced to 100 $\mathrm{mg} / \mathrm{day}$ then to $50 \mathrm{mg} / \mathrm{day}$. ESS score was 7 and the complaint of sleepiness did not affect her daily life. Sexual desire returned to normal with the decrease in modafinil dose.

\section{Discussion}

There are many causes of EDS (excessive daytime sleepiness), including drugs, toxins, metabolic derangements, respiratory causes such as obstructive sleep apnea, and structural lesions such as stroke or head injury [9]. In our case, no pathophysiological sate was detected in neurological, ENT and respiratory disease evaluations and clinical presentation and polysomnographic evaluation were compatible with idiopathic hypersomnia, which suggested this diagnosis. Modafinil treatment brought about a pronounced improvement in day time sleepiness and ESS values. However, approximately one week after the initiation of $200 \mathrm{mg} /$ day modafinil, a marked increase in sexual desire occurred.

Although hypersexuality can be caused by some medical conditions or medications, in most cases the cause is unknown. As defined in the DSM-IV-TR, hypersexuality can be a symptom of hypomania or mania in bipolar disorder or schizoaffective disorder. Several neurological conditions such as Alzheimer's disease, various types of brain injury, Klüver-Bucy syndrome, Kleine-Levin syndrome and many more neuro-degenerative diseases can cause hypersexual behavior. Pick's disease causes damage to the temporal/frontal lobe of the brain; people suffering with Pick's disease show a range of socially inappropriate behaviors. Hypersexuality has also been reported to result as a side-effect of some medications used to treat Parkinson's disease. Some street drugs, such as methamphetamine, may also contribute to hypersexual behavior [10-16].

Hypersexuality and hypersomnia may coexist with Klüver-Bucy and Klein Levin syndromes. Our patient did not have sleepiness in arracks, and did not have accompanying hyperphagia and hyperorality, which excludes these diagnoses. 
In our case, there was no history of psychiatric disease, brain trauma or neurodegenerative disease symptom which can lead to development of hypersexual behavior.

Hypersexuality has not been reported as a side effect of modafinil yet. Unfortunately the pathophysiological mechanism of modafinil induced hypersexuality is not clear.

Pathogenic overactivity of the dopaminergic mesolimbic pathway in the brain--forming either psychiatrically, during mania, or pharmacologically, as a side effect of dopamine agonists, specifically $\mathrm{D}_{3}$-preferring agonist-- is associated with various addictions and sometimes hypersexual behavior [17-19]. High dose use may induce the development of hypersexuality by increasing dopamin. The fact that increase in sexual desire arising with $200 \mathrm{mg} /$ day dose regressed when the dose was reduced to $50 \mathrm{mg}$ /day supports this hypothesis. In conclusion, clinicians should be aware of this rare significant side effect of modafinil and should maintain treatment with the lowest possible dose.

\section{References}

[1] Köroğlu E, Güleç C. Textbook of psychiatry. Physician Publishing Associatiın ; 2 nd edn, Ankara 2007.

[2] Morgenthaler, T. I., Kapur, V. K., Brown, T., Swick, T. J., Alessi, C., Aurora, R. N., Boehlecke, B., Chesson AL Jr., Friedman, L., Maganti, R., Owens, J., Pancer, J., and Zak, R. 2007. "Standards of Practice Committee of the AASM. "Practice Parameters for the Treatment of Narcolepsy and other Hypersomnias of Central Origin.” Sleep 30 (12) 1705-11.

[3] Ishizuka, T., Murotani, T., and Yamatodani, A. 2010. "Modanifil Activates the Histaminergic System through the Orexinergic Neurons." Neurosci. Let. 483 (3): 193-6.

[4] Huang, Z. J., and Di Cristo, G. 2008. "Time to Change: Retina Sends a Messenger to Promote Plasticity in Visual Cortex." Neuron. 59 (3): 355-8.

[5] Gass, J. T., and Olive, M. F. 2008. "Glutamatergic Substrates of Drug Addiction and Alcoholism." Biochem. Pharmacol. 75 (1): 218-65.

[6] Minzenberg, M. J., Watrous, A. J., Yoon, J. H., Ursu, S., and Carter, C. S. 2008. "Modafinil Shifts Human Locus Coeruleus to Low-Tonic, High-Phasic Activity during
Functional MRI.” Science 322 (5908): 1700-2.

[7] Volkow, N. D., Fowler, J. S., Logan, J., Alexoff, D., Zhu, W., Telang, F., Wang, G. J., Jayne, M., Hooker, J. M., Wong, C., Hubbard, B., Carter, P., Warner, D., King, P., Shea, C., Xu, Y., Muench, L., and Apelskog-Torres, K. 2009. "Effects of Modafinil on Dopamine and Dopamine Transporters in the Male Human Brain: Clinical Implications." Jama. 301 (11): 1148-54.

[8] Whitmore J., Hickey P., Doan B., Harrison R., Kisner J., Beltran T., McQuade J., Fischer J., Marks F. 2006 "A Double-Blind Placebo-Controlled Investigation of the Efficacy of Modafinil for Maintaining Alertness and Performance in Sustained Military Ground Operations." Air Force Research Lab Brooks AFB TX Human Effectiveness Dir/Biodynamics And Protection Div United States Air Force Research Laboratory.

[9] Shneerson, J. M. 2005. Sleep Medicine: A Guide to Sleep and its Disorders. 2nd ed., London: Blackwell Publishing 125-60.

[10] Dhikav, V., Anand, K., and Aggarwal, N. 2007. "Grossly Disinhibited Sexual Behavior in Dementia of Alzheimer's Type." Arch. Sex. Behav. 36 (2):133-4.

[11] Miller, B. L., Cummings, J. L., McIntyre, H., Ebers, G., and Grode, M. 1986. "Hypersexuality or Altered Sexual Preference Following Brain Injury." J. Neurol. Neurosurg. Psychiatr. 49 (8): 867-73.

[12] Arnulf, I., Zeitzer, J. M., File, J., Farber, N., and Mignot, E. 2005. "Kleine-Levin Syndrome: A Systematic Review of 186 Cases in the Literature." Brain. 128 (12): 2763-76.

[13] Cummings, J. L. Dementia: A Clinical Approach. 2nd ed., Boston: Butterworth-Heinemann.

[14] Vogel, H. P., and Schiffter, R. 1983. "Hypersexuality-A Complication of Dopaminergic Therapy in Parkinson's Disease." Pharmacopsychiatria 16 (4): 107-10.

[15] Uitti, R. J., Tanner, C. M., Rajput, A. H., Goetz, C. G., Klawans, H. L., and Thiessen, B. 1989. "Hypersexuality with Antiparkinsonian Therapy." Clin. Neuropharmacol. 12 (5): 375-83.

[16] Mansergh, G., Purcell, D. W., Stall, R., McFarlane, M., Semaan, S., Valentine, J., and Valdiserri, R., 2006. "CDC Consultation on Methamphetamine Use and Sexual Risk Behavior for HIV/STD Infection: Summary and Suggestions." Public Health Rep. 121 (2): 127-32.

[17] Silverstone, T. 1985. "Dopamine in Manic Depressive Illness. A Pharmacological Synthesis." J. Affect. Disord. 8 (3): 225-31.

[18] Boyd, A. 1995. "Bromocriptine and Psychosis: A Literature Review." Psychiatr. Q. 66 (1): 87-95.

[19] Arias-Carrión, Ó., and Pöppel, E. 2007. "Dopamine, Learning, and Reward-Seeking Behavior." Act. Neurobiol. Exp. 67 (4): 481-8. 